\title{
Assessment of PLS-SEM Path Model for Coefficient of Determination and Predictive Relevance of Consumer Trust on Organic Cosmetics
}

\author{
Suhan* and Anantha Padmanabha Achar ${ }^{\dagger}$
}

\begin{abstract}
In this paper the researchers investigated the coefficient of determination R-Square and predictive relevance $\left(\mathrm{Q}^{2}\right)$ through Blindfolding. To fulfil the aim of the study, a structured quantitative research survey has been conducted with 640 sample size. The results emerged from the research survey shows that the R-Square has moderate strength for the endogenous latent variable trust and substantial strength or effect for the endogenous latent variables integrity, ability and benevolence. After calculating $\mathrm{Q}^{2}$ for the endogenous latent variable ability, benevolence, integrity and trust it was found that the model has predictive relevance for these constructs. The path coefficient threshold values for measuring between indicators namely, cause purview and emotional benefits, cause consequential and trust, cause rubric and trust, cause span and emotional benefits, emotional benefits and trust, functional benefits and trust, ability and trust, benevolence and trust and also for integrity and trust are above the threshold value of 1.96 substantiate the hypothesis and exerts direct relationship between two
\end{abstract}

\footnotetext{
* Research Scholar, Jain University, Bangalore and Assistant ProfessorSelection Grade, School of Management, Manipal Institute of Technology, Manipal University, Manipal, Karnataka, India

† Corresponding Author, Dean, Justice K S Hegde Institute of Management, Nitte University, Karkala, Udupi District, Karnataka, India; apmanipal@gmail.com
} 
variables. But the path coefficient threshold values between indicators namely, Cause purview and trust, cause consequential and trust, cause rubric and emotional benefits, cause span and trust, and also self-expressive and trust are below the threshold value of 1.96 does not substantiate the hypothesis and also does not exerts direct relationship between two variables. At the end of the paper, the author highlights the results, along with implications and limitations.

Keywords: Predictive Relevance, R-Square, Endogenous, Exogenous, Moderate, Substantial

\section{Introduction}

Organic cosmetic products are playing a very vital role in a highly developed economy because people are much aware of it, which is totally opposite in developing and underdeveloped economy. In Indian economy general cosmetic products and companies are much more known to the public than organic cosmetics products and companies. Choosing general cosmetic company is products for people in developing economy is primarily based on the cost of the commodity, different features which brand carry, people status level, existence of competitors and their products, popularity of brand at local, domestic and international level (Rajagopal, 2007). But organic cosmetic products and company varies from general cosmetic products and company mainly from its environmentally friendly production and quality. Its packaging and campaigns are very much concerned about environmental issues. (Bryn Jones, 1991). In developing countries like India varieties of non-organic cosmetics companies are playing a vital role and in order to come out of such non-organic cosmetics companies stiff and cut-throat competition, it is essential for any organic cosmetic companies to use cause-related marketing (CrM) strategies effectively and efficiently as an instrument of corporate social responsibility which will create trust in the minds of people (Polonskey and Jevons, 2006). Cause-identification, cause-importance and cause-fit create high level of trust and loyalty among consumers (Maignan et al, 1999). 


\section{Literature Review}

\section{Cause Campaign}

Cause-Related Marketing (CRM) are featured by an action from corporates to commit a stated amount to a specific or certain cause when consumers employ in revenue generation that fulfils corporate and individual's objectives (Varadarajan and Menon, 1988). Local (regional), National (domestic) and International (Global) are the three kinds of cause purview (CP) propounded by Varadarajan and Menon in 1988. Local cause plays vital role compared to national and international cause in USA(Cone, Inc 1999) and China(Hou et al, 2008). But research also reveals that cause purview has meager or no role in CRM campaign (Ross et al, 1992; Cui et al, 2003). Cause rubric (CR) has classified in to primary and secondary cause purview. Primary cause involves human's fundamentals whereas secondary cause involves upliftment of society (Denton, John.A, 1990; Kotler \& Lee, 2005). Primary cause is liable for profit and advancement of corporates (Szykman, 2004). Primary cause plays vital role than secondary cause purview in strengthening emotional benefits and trust of consumers (Williams and Barrett, 2000: Cornwell and Coote, 2005). Cause consequential (CC) factors of CSR campaign must switch more towards sudden catastrophe than on-going one, which build up trust in consumers (Petty and Cacioppo, 1984; Maon et al 2009; Ratliff, 2007;Carrol and McCombs, 2003).

Cause span (CS) is all about duration of cause campaign. Research shows that longer duration of cause campaign has created trust better than shorter duration (Varadarajan and Menon, 1998; Douwe van den Brink et al, 2006). But research also shows that cause span has no act in formation of trust (Emmanuel Che'ron et al, 2012). Normally energetic and forceful campaign stands for long time (Welsh, 1999). But narrow and shortened campaign stands for short time (Van Den Brink et al, 2006).

\section{Emotional Benefits (EB)}

For the theoretical and practical purpose researcher has put forward numerous ambit of research on emotion and emotional benefits. Cause campaign may elicit desire aspect of emotion (Strahilevitz and Myers, 1998). Robert Plutchik (1980) has 
innovated wheel of emotion with eight elements of progressive emotions like surprise, anger, anticipation, disgust, fear, trust, sadness, and joy. Emotional benefits add consumers with a positive feeling when they purchase or utilize a particular brand (Aaker, 1996). It's very essential to bring emotional factors it is an expensive product for gaining trust (Kapferer and Bastien, 2009). Mixture of anger, guilt and excitement leads to different forms of anxiety and induces people to trust a brand and purchase (Gray 1982; Oatley and Johnson-Laird, 1987). Affective component highlights consumer preference towards brand is based on positive and negative emotions that they develop (Douwe van den brink et al, 2006).

\section{Self-Expressive Benefits (SEB)}

Self-expressive benefits where brands appreciate one's social self and also it echo's one's inner-self (Carrol and Ahuvia A.C, 2006). The main purpose of self-expressive functions of the product is to manage social status (Veblen, 1899). Research also articulates that self-expressive functions of brand reflects uniqueness to the consumers (Amaldoss and Jain 2005; Berger and Ward 2010). Inner self (How I would like to see myself) is concerned about individual's self-apprehension where as social self (How I would like other's to see me) is all about interdependent self-apprehension (Trafimow et al, 1991).

\section{Functional Benefits (FB)}

Functional benefits are the features of the product that enhances the prospect/consumer with functional utility (Aaker D.A, 1996). Symbolic and functional utilities are one of the major factors which highlights brand image (James Mowle and Bill Merrilees, 2005). Functional benefits of products also maximizes consumer's expectations and needs (De Chernatony,L. et al., 2000, Bhat and Reddy.,1998). Brand positioning will be very strong when the functional benefit derived by customer through product is high (Park et al., 1986).

\section{Trust}

Both trust and loyalty can be strengthened through effective cause campaign (Maignan et al, 1999).The marketing concept of buying 
and retaining customers plus repetition in buying can be successful with efficient CRM campaign (Zeithaml et al, 1996). Ability (ABI), benevolence(BEN) and integrity (INT) trust is propounded by Mayer et al, 1995). ABI are the parts of trust (Colquitt et al, 2007; Mayer et al, 1995). Trust plays a vital role along with strong campaign and created a effective relationship between consumers and corporates (Urban et al, 2000). Research also highlights that trust is nothing but positive perceptions of people (Hawes et al, 1989). Campaign of corporates in honest ways induces consumers trust (Doney and Cannon, 1997).

\section{Research Method}

The present research adopted a descriptive research design using the survey method. The study design that was adopted in this research work, is a cross sectional approach, where consumers are contacted at chosen retail outlet and data pertaining to research is collected directly from the subjects. The research instrument has been branched into five major parts. The initial part of the questionnaire assessed the effectiveness of the cause campaign. The second segment assessed emotional benefits. The third segment assessed functional benefits. The fourth segment assessed self-expressive benefits and the fifth gathered data on trust. Rensis Likert five point scale was used in the questionnaire. The survey instrument used in this research is a structured questionnaire. In the beginning Cronbach's alpha ( $\alpha$ ) is calculated to measure reliability. Later stage reliability is measured with the value of composite reliability. This study was undertaken at chosen retail outlets which sell only organic cosmetics and located in Mangalore, Bangalore and Mysore districts of Karnataka. A purposive sampling technique was employed by adopting inclusion criteria to ensure that respondent bias is eliminated from those clients who are buying organic cosmetics for below two years. Only those customers who have been buying organic cosmetics for more than two years, who are systematic in their buying approach, subjects who are aware of organic cosmetic benefits and subjects who are aware of the importance of cause campaign, have been included in this study. Sample size was determined using the formula

$$
Z^{2}{ }_{\alpha} \times p^{*} q
$$




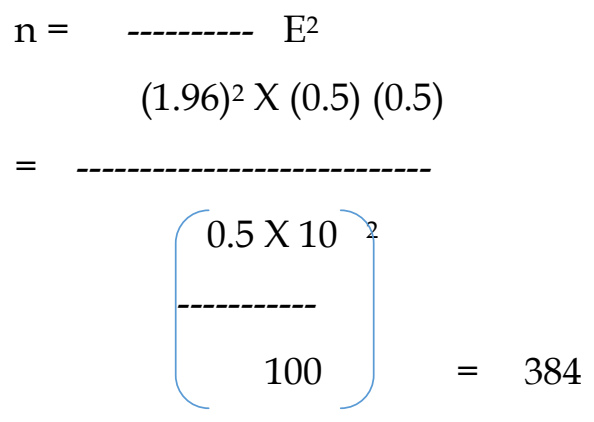

$10 \%$ of non-response $384 /(90 / 100)$

$$
384 / 0.9=427
$$

$Z_{\alpha}=95$ percentage of confidence level $=1.96$

$E=10$ percent of error ( $90 \%$ power) with $10 \%$ non-response

$\mathrm{p}=$ proportion to organic cosmetic buyer

$\mathrm{q}=1-\mathrm{p}$

Since various aspects differ among Mangalore, Bangalore and Mysore the design effect propounded by Leslie Kish is used which lies in between the value 1.5 to 2 . In this research, the researcher has taken design effect value of 1.5

So the sample size will be

$427 * 1.5=640$

So sample size $\mathrm{n}=640$

Two stage sampling methods, namely random sampling of lottery method for selection of outlets and purposive sampling for the selection of consumers is done. In selection of outlets 50 percentage of total cluster of outlets has been chosen i.e. 10 out of 19 outlets. Random sample lottery method is used. Random numbers obtained is used to build the list of random numbers. Numbers were randomly selected from within the range of 1 to 19 . No duplicate numbers is allowed. So random number obtained are 18, $01,09,11,08,19,17,13,06$ and 15.

Regarding the customer sampling, the sample size divisions in three districts are done as follows and equal representation of random population has been done. 
Bangalore $=7 / 10 * 640=448$ customers $=448 / 7=64$ customers per outlet

Mangalore $=2 / 10^{*} 640=128$ customers $=128 / 2=64$ customers per outlet

Mysore $=1 / 10 * 640=64$ customers $=64 / 1=64$ customers per outlet.

Respondents were briefed on the objectives of the research work and then administered the questionnaire. Six hundred and forty clients, who fulfilled the inclusion criteria, were selected to participate in the survey. PLS-SEM(Partial Least Square-Structural Equation Modeling) was employed to test the convergent validity, discriminant validity, estimation of collinearity, measure the model variables variance, assess the path model with inclusion of mediating variables, calculate variance accounted for (VAF) and conclusions were drawn.

\section{Summary of Reflective Measurement Model}

Hair et al. (2014) guides the reflective measurement models needs to be estimated on their internal consistency reliability and validity. The reliability is measured by Cronbach's alpha and composite reliability. Cronbach alpha values are considered in the beginning stage of the research where its value should be above 0.7 and composite reliability used in the later stage of research with value which should be above 0.8 (Henseler et al., 2009). The determination of threshold value for the composite reliability is based on purpose of the research. If the purpose of the research is exploratory in nature then threshold value should be equal to or greater than 0.6 (Chin, 1998; Höck \& Ringle, 2006). If the purpose of research is confirmatory then threshold value has become a debatable issue because some researchers proposed threshold value equal to or greater than 0.7 (Henseler, Ringle, \& Sarstedt, 2012: 269) and some researchers proposed threshold value equal to or greater than 0.8 (Daskalakis \& Mantas, 2008). The exogenous latent variables namely, local cause, national cause, on-going cause, sudden cause, primary cause, secondary cause, regular cause, negative emotions, positive emotions, inner-self, social-self, health consciousness and store values are $0.909,0.913,0.870,0.867,0.831$, $0.863,1,0.907,0.885,0.885,0.926,0.873$ and 0.863 respectively indicating internal consistency reliability orcomposite reliability is 
established. Similarly, the endogenous latent variables namely, ability, benevolence and integrity values are $0.879,0.911$ and 0.897 established composite reliability by crossing above the threshold value 0.7 (Table: 1 ).

The convergent validity is considered using the average variance extracted (AVE) and the outer loadings of the indicators. By convention, for a well-fitting reflective model, path loadings also known as outer loadings should be above 0.70 , the threshold value (Henseler, Ringle, \& Sarstedt, 2012) which is established in this model. The exogenous latent variables like local cause, national cause, on-going cause, sudden cause, primary cause, secondary cause, regular cause, negative emotions, positive emotions, innerself, social-self, health consciousness and store has AVE value $0.834,0.725,0.691,0.765,0.710,0.677,1,0.660,0.607,0.659,0.758$, $0.775,0.767$ respectively. Finally, in the case of endogenous latent variable like ability, benevolence and integrity, the AVE values are $0.707,0.773$ and 0.744 . For both exogenous and endogenous latent variables AVE values are higher than 0.5 , which shows that there is a high level of convergent validity is established (Table: 1 ).

\section{Discriminant Validity through Fornell Lacker Criterion}

Discriminant validity can be assessed using Fornell-Lacker criterion, wherein the square root of the AVE values is compared with the latent variable correlations and the rule is AVE should be greater than its highest correlation with any other construct. In evaluating and reporting the results, ground rules for PLS-SEM as given by Hair et al. (2014) is followed, estimating the measurement models before assessing the structural model. To establish discriminant validity the square root of every construct's AVE must be bigger than its correlation with other constructs. As shown in the table, the diagonal value shows the square root of AVE of the construct, which is higher than the other correlation values establishing discriminant validity. The discriminant validity is established by taking in to consideration the square root value of each construct's AVE. This value must be larger in its correlation when compared with other constructs. As shown in the table the square root value of the exogenous latent variables namely, health consciousness, inner-self, local cause, national cause, negative 
emotions, on-going cause, positive emotions, primary cause, regular cause, sudden disaster, secondary cause, social-self and store are $0.880,0.812,0.913,0.851,0.813,0.831,0.779,0.843,1,0.874$, $0.823,0.871$ and 0.876 respectively. Similarly, the square root value of the endogenous latent variables namely, ability, benevolence and integrity are $0.841,0.879$ and 0.863 respectively which is higher than the other correlation values establishing discriminant validity (Table:2).

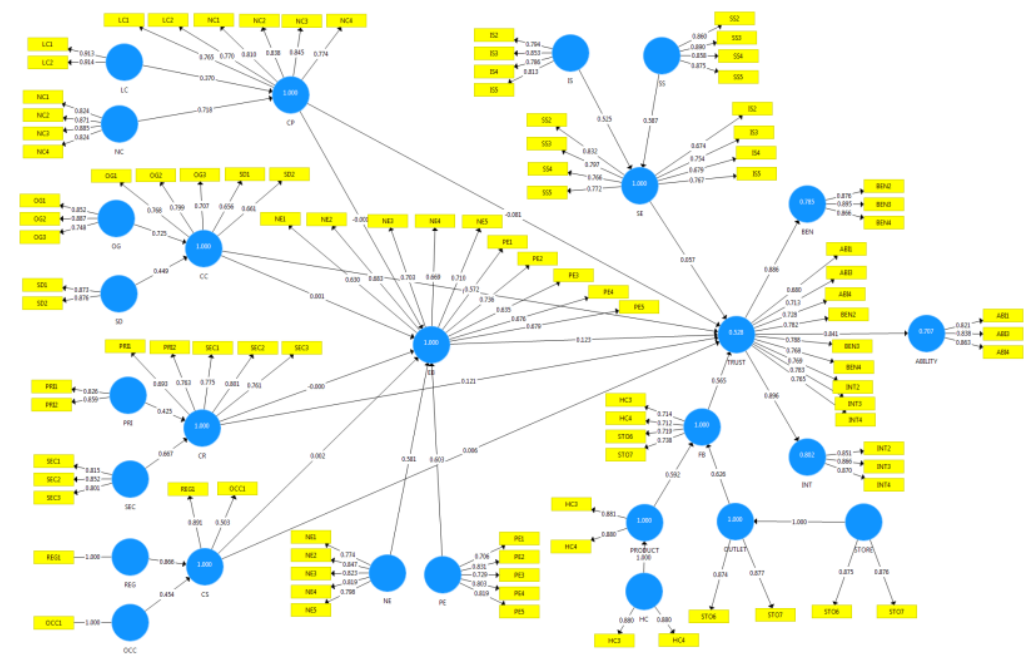

Fig: 1 Measurement Model

\section{Illustration of Measurement Model Variable Variance}

The reflective model indicates, $R^{2}$, which is the determination of coefficient, has value of 0.528 for the endogenous latent variable, trust. This implies that the seven exogenous latent variables namely cause purview, cause consequential, cause rubric, cause span, emotional benefits, self-expressive benefits and functional benefits moderately explain $52.8 \%$ of the variance in endogenous latent variable trust. The reflective model indicates, $R^{2}$, which is the determination, $R^{2}$, is $0.707,0.785$ and 0.802 for the exogenous latent variable, ability, benevolence and integrity. This means that the seven exogenous latent variables namely cause purview, cause consequential, cause rubric, cause span, emotional benefits, self- 
expressive benefits and functional benefits substantially explain $70.7 \%, 78.5 \%$ and $80.2 \%$ of the variance in its endogenous latent variable ability, benevolence and integrity respectively (Fig:1). The threshold value above $0.67,0.33$ and 0.19 indicates to be "substantial", "moderate" and "weak" model respectively (Chin 1998; Höck \& Ringle, 2006).

\section{Predictive Relevance $\left(\mathrm{Q}^{2}\right)$ Through Blindfolding and Coefficient of Determination $\left(R^{2}\right)$}

The central criterion for the structural model's estimation is the determination of coefficient $\mathrm{R}^{2}$ (Henseleret al., 2012), which as shown in the above table. The high $\mathrm{R}^{2}$ value substantiates the model's predictive accuracy and describes results above the cutoffs 0.67, 0.33 and 0.19 to be "substantial", "moderate" and "weak" respectively (Chin 1998, Höck \& Ringle, 2006). The endogenous latent variable ability, benevelonce and integrity the $\mathrm{R}^{2}$ values are $0.707,0.785$ and 0.802 respectively describes that present model is substantial but with regard to the endogenous latent variable trust, the $\mathrm{R}^{2}$ value is 0.528 which describes that model is moderate with trust construct. In addition to the coefficient of determination $\mathrm{R}^{2}$, Hair et al. (2014) recommend to compute the Stone-Geisser's $\mathrm{Q}^{2}$ value (Geisser, 1974; Stone, 1974) for measuring the model's predictive relevance. As directed by Hair et al. (2014) the $\mathrm{Q}^{2}$ value is obtained using the blindfolding procedure with certain omission distance, such that $\mathrm{Q}^{2}$ value larger than zero indicate that the model has predictive relevance for a certain endogenous construct. For calculating $\mathrm{Q}^{2}$ the omission distance of 7 was considered obtaining the $Q^{2}$ value of $0.497,0.606,0.596$ and 0.296 for the variables ability, benevolence, integrity and trust which implies that the model has predictive relevance for this construct (Table:3).

\section{Assessment of PLS Path Model Without the Inclusion of Mediators}

The direct effect of independent variables on mediating variables as well as on dependent variables were investigated. Further, the relationship between two constructs is found to be significant at $5 \%$ level of significance when the empirical $t$ value of for two indicators is above the threshold value of 1.96. Therefore, it reveals that the path coefficient threshold values above 1.96 substantiate 
the hypotheses that independent variables exercise direct effect on mediating variables as well as on direct variables. From the above table the path coefficient threshold values for two indicators namely, cause purview and emotional benefits, cause consequential and trust, cause rubric and trust, cause span and emotional benefits, emotional benefits and trust, functional benefits and trust, ability and trust, benevolence and trust and also integrity and trust are above 1.96 substantiate the hypothesis and exerts direct relationship between these two variables. But the path coefficient threshold values for two indicators namely, Cause purview and trust, cause consequential and trust, cause rubric and emotional benefits, cause span and trust, and also self-expressive and trust are below the threshold value 1.96 does not substantiate the hypothesis and also does not exert direct relationship between these two variables (Table:4).

\section{Managerial Implications and Conclusion}

In the end, we observed that R-Square value for endogenous latent variable, trust has moderate effect when compared with its sub constructs ability, integrity and benevolence which has substantiate effect. However, it is still significantly relevance with no indication of collinearity. Therefore, we argue that all utilized measures provide strong contribution to the impact construct like cause purview and emotional benefits, cause consequential and trust, cause rubric and trust, cause span and emotional benefits, emotional benefits and trust, functional benefits and trust, ability and trust, benevolence and trust and also integrity and trust should be retained.

With regard to the endogenous latent variable the $R^{2}$ value is 0.528 which describes that model is moderate with trust construct. So corporates need to maintain it and make moderate effect model to substantial effect by strengthening the cause campaigns like against animal testing, support community trade, defend human rights, activate self-esteem and protect the planet by working on environmental issues.

The model consist of 7 exogenous latent variables and 43 indicators which can be used to measure the impact of it on one endogenous latent variable namely, Trust and its 9 indicators. This proposition 
is based on indicator loading, indicator reliability, composite reliability, convergent validity, discriminant validity, $\mathrm{R}^{2}$ and $\mathrm{Q}^{2}$ value with measurement and structural model.However, rather than using just one method for giving such kind of strategic decisions, comparison of the findings that are obtained by alternative methods might offer more accurate assessments. Therefore, in the forthcoming studies, alternative methods and their findings can be compared. Moreover, such studies which aim to examine the cause campaign, current product or service features, are generally deficient to offer to the managers what kind of effective and right campaign and new product or service features might be added to the current one in the future. That approach concentrate on categorization of the current features and their preferences in terms of resource allotment. Samples were mostly collected from the three districts namely, Bengaluru, Mangalore and Mysore in Karnataka state, India. So work needs to be done to extend the scope of the research by including other areas. Future research study should take further steps to examine the role of cause amount construct and to identify their effect on the model.

\section{References}

Aaker, D.A. (1996).Building Strong Brands, The Free Press, New York, NY.

Amaldoss, Wilfred and Sanjay Jain. (2005).Conspicuous Consumption and Sophisticated Thinking. Management Science, 51 (10), 1449-66.

Bhat.S. and Reddy, S.K. (1998).Symbolic and functional positioning of brands. Journal of consumer marketing, 15(1), 32-43.

Bryn Jones. (1991).Green Consumerism and the Supermarkets. British Food Journal, 93(3), 8-11.

Carroll, Barbara A., and Ahuvia, Aron C. (2006).Some Antecedents and Outcomes of Brand Love. Marketing Letter, 17, 79-89.

Carrol and McCombs. (2003).Agenda setting effective business news on the public's image and opinions about major corporations. Corporate reputation review, 6 (1), 36-46.

Chin, W. W. (1998). The partial least squares approach for structural equation modeling. Pp. 295-336 in Macoulides, G. A., 
ed. Modern methods for business research. Mahwah, NJ: Lawrence Erlbaum Associates.

Colquitt, J.A., Scott, B.A. and LePine, J.A. (2007). Trust, trustworthiness, and trust propensity: A meta-analytic test of their unique relationships with risk taking and job performance. Journal of Applied Psychology, 92(4), 909-26.

Cornwell,T.B., \& Coote, L.V.(2005).Corporate sponsorship of a cause: The role of identification in purchase intent. Journal of business research, 58(3), 268-276.

Cui, Y.,Trent,E.S., Sullivan,P.M.., and Maitru, G.N.(2003). Causerelated marketing: How generation $\mathrm{Y}$ responds. International Journal of Retail and Distribution management, 31(6/7), 310-320.

Daskalakis, Stylianos \& Mantas, John (2008). Evaluating the impact of a service-oriented framework for healthcare interoperability. Pp. 285-290 in Anderson, Stig Kjaer; Klein, Gunnar O.; Schulz, Stefan; Aarts, Jos; \& Mazzoleni, M. Cristina, eds. eHealth beyond the horizon - get IT there: Proceedings of MIE2008 (Studies in Health Technology and Informatics). Amsterdam, Netherlands: IOS Press.

De Chernatony, L., Harris, F and Dall'Olmo Riley,F (2000).Added value: Its nature and sustainability. European journal of marketing, 34(1/2), 39-56.

Denton, John.A. (1990).Society and the official world: A reintroduction to sociology, Dix Hills, N.Y: General Hall, P.17, ISBN 0-93093094-6.

Doney.P.M and Cannon.J.P. (1997). An examination of the nature of trust in the buyer seller relationships. Journal of Marketing, 61, 35-51.

Douwe Van Den Brink, Gary Odekerken-Schroder and Pieter Pauwels. (2006). cause related marketing. Journal of consumer marketing, 23(1), 15-25.

Emmanuel Cheron, Florian Kohlbacher and Kaoru Kusuma. (2012). Consumer perception of cause-related marketing in Japan. Journal of Consumer Marketing,29 (5), 357-368.

Geisser, S. (1974). A predictive approach to the random effects model. Biometrika, 61(1), 101-107. 
Gray, J. A. (1982). The neuropsychology of anxiety. Oxford: Oxford University Press.

Hair, J.F., Hult, G.T.M., Ringle, C.M. and Sarstedt, M. (2014). A Primer on Partial Least Squares Structural Equation Modeling, Sage, Thousand Oaks, CA.

Hawes,J.M, Mast.K.E and Swan,J.E.(1989).Trust earning perceptions of sellers and buyers. Journal of personal selling and sales management, 9(1-8).

Henseler, J., Ringle, C.M. and Sinkovics, R.R. (2009). The use of partial least squares path modeling in international marketing. Advances in International Marketing, 20, 277-320.

Henseler, Jörg Ringle, Christian M. \& Sarstedt, Marko. (2012). Using partial least squares path modeling in international advertising research: Basic concepts and recent issues. Pp. 252276 in Okzaki, S., ed. Handbook of partial least squares: Concepts, methods and applications in marketing and related fields. Berlin: Springer.

Höck, Michael \&Ringle, Christian M. (2006). Strategic networks in the software industry: An empirical analysis of the value continuum. IFSAM VIIIth World Congress, Berlin 2006. Retrieved 2/22/2009 from http://www.iblunihh.de/IFSAM06.pdf.

Hou, J.,Du,L.,\& Li,J. (2008). Causes attribute influencing consumer's purchasing intention: Empirical evidence from China. Asia pacific journal of marketing and logistics, 20(4), 363380.

James Mowle and Bill Merrilees.(2005). A functional and symbolic perspective of branding. Journal of product and brand management, 14(4), 220-227.

Kapferer, J. N., \&Bastien, V. (2009). The luxury strategy: Break the rules of marketing to build luxury brands. London: Kogan Page.

Kotler, P., \& Lee,N. (2005). Corporate social responsibility: Doing the most good for your company and your cause. Hoboken: John Wiley \& Sons. 
Maignan.I, Ferrell.O.C. and Hult.(1999).Corporate citizenship: Cultural antecedents and business benefits. Journal of academy of marketing science, 27, 455-469.

Maon,F., Lindgreen,A., and Vanhamme,J. (2009). Developing supply chain in disaster relief operations through croos-sector socially oriented collaborations: A theoretical model. Supply chain management, 14(2), 117-127.

Mayer, R.C., Davis, J.H. and Schoorman, F.D. (1995). An integrative model of organizational trust. The Academy of Management Review, 20(3), 709-34.

Oatley, K., \& Johnson-Laird, P. N. (1987). Towards a cognitive theory of emotions. Cognition \& Emotion, 1, 29-50.

Park.C.W., Jaworski,B.J. and MacInnis.D.J. (1986).Strategic brand concepts image management. Journal of marketing, 50,135-45.

Petty, Richard E. and John T. Cacioppo.(1984). The effects of involvement on responses to argument quantity and quality: Central and pherpheral routes to persuasion.Journal of personality and social psychology, 46(1), 69-81.

Plutchik, R. (1980). A general psychoevolutionary theory of emotion. In R. Plutchik \& H. Kellerman (Eds.), Emotion: Theory, research, and experience." Vol. 1. Theories of emotion (pp. 3-31). New York: Academic Press.

Polonsky, M.J. and Jevons, C. (2006). Understanding issue complexity when building a socially responsible brand. European Business Review,18(5),340-9.

Rajagopal. (2007). Buying decisions towards organic products: An analysis of customer value and brand drivers. International journal of emerging markets, 2(3),236-251.

Ratliff,D. (2007). The challenge of humanitarian logistics", operations research/management science today, December, 31.

Ross,J.K., IIIStutts, M.A.,and Patterson, L.T.(1992).Consumer perception of organizations that use cause-related marketing. Journal of the academy of the marketing science, 20(1),93-97.

Stone, M. (1974). Cross-validatory choice and assessment of statistical predictions. Journal of the Royal Statistical Society, 36(2),111-147. 
Strahilevitz, M. and Myers, J.G. (1998).Donations to charity as purchase incentives: how well they work may depend on what you are trying to sell. Journal of Consumer Research, 24(4), 434-46.

Szykman, L.R. (2004).Who are you and why are you being nice? Investigating the industry effect on consumer reaction to corporate societal marketing efforts. in Kahn, B. and Luce, M.F.

Trafimow David, Harry C. Triandes and Sharon.G.Goto. (1991).Some tests of the distinction between the private self and collective self. Journal of personality and social psychology, 60, 649655.

Urban.G.L, Sultan,F. and Qualls.W.J.(2000). Placing trust at the center of your internet strategy. Sloan management review, 42, 3949.

Van den brink,D., Odekerken-schroder, G. and Pauwels.P.(2006). The effects of strategic and tactical cause related marketing on consumers' brand loyalty.Journal of consumer marketing, 23(1),1525.

Varadarajan andMenon,A. (1988). Cause related marketing: A coalignment of marketing strategy and corporate philanthropy.Journal of marketing, 52(3),58-74.

Veblen, Thorstein. (1899). The Preconceptions of Economic Science.Quarterly Journal of Economics, 13 (4), 396-426.

Welsh, J.C. (1999). Good cause, good business. Harvard Business Review, 77(5), 21-4.

Williams, R.J. and Barrett.J.D. (2000). Coprorate philanthropy, Criminal activity and firm reputation: Is there a link?.Journal of business Ethics, 26(4),341-350.

Zeithaml V.A, Berry.L. and Parasuraman.A. (1996). The behavioural consequences of service quality. Journal of Marketing, 60, 31-46. 


\section{Annexure:}

Table 1. Summary of Reflective Measurement Model

\begin{tabular}{|c|c|c|c|c|c|}
\hline Latent Variables & Indicators & Loadings & $\begin{array}{c}\text { Indicator } \\
\text { Reliability }\end{array}$ & $\begin{array}{l}\text { Composite } \\
\text { Reliability }\end{array}$ & AVE \\
\hline \multicolumn{6}{|c|}{ Cause purview } \\
\hline \multirow{2}{*}{ Local cause } & LC1 & 0.913 & 0.833 & \multirow{2}{*}{0.909} & \multirow{2}{*}{0.834} \\
\hline & LC2 & 0.914 & 0.835 & & \\
\hline \multirow{4}{*}{ National cause } & NC1 & 0.824 & 0.678 & \multirow{4}{*}{0.913} & \multirow{4}{*}{0.725} \\
\hline & NC2 & 0.871 & 0.758 & & \\
\hline & NC3 & 0.885 & 0.783 & & \\
\hline & NC4 & 0.824 & 0.678 & & \\
\hline \multicolumn{6}{|c|}{ Cause consequential } \\
\hline \multirow{3}{*}{ On-going cause } & OG1 & 0.852 & 0.725 & \multirow{3}{*}{0.870} & \multirow{3}{*}{0.691} \\
\hline & OG2 & 0.887 & 0.786 & & \\
\hline & OG3 & 0.748 & 0.559 & & \\
\hline \multirow{2}{*}{ Sudden cause } & SD1 & 0.873 & 0.762 & \multirow{2}{*}{0.867} & \multirow{2}{*}{0.765} \\
\hline & SD2 & 0.876 & 0.767 & & \\
\hline \multirow[b]{3}{*}{ Primary cause } & \multicolumn{3}{|c|}{ Cause rubric } & \multirow{2}{*}{0.831} & \multirow{3}{*}{0.710} \\
\hline & PRI1 & 0.826 & 0.682 & & \\
\hline & PRI2 & 0.859 & 0.737 & 0.831 & \\
\hline \multirow{3}{*}{ Secondary cause } & SEC1 & 0.815 & 0.664 & \multirow{3}{*}{0.863} & \multirow{3}{*}{0.677} \\
\hline & SEC2 & 0.852 & 0.725 & & \\
\hline & SEC3 & 0.801 & 0.641 & & \\
\hline \multicolumn{6}{|c|}{ Cause span } \\
\hline Regular & REG1 & 0.891 & 1.000 & 1.000 & 1.000 \\
\hline \multicolumn{6}{|c|}{ Emotional benefits } \\
\hline \multirow{5}{*}{ Negative emotions } & NE1 & 0.774 & 0.599 & \multirow{5}{*}{0.907} & \multirow{5}{*}{0.660} \\
\hline & NE2 & 0.847 & 0.717 & & \\
\hline & NE3 & 0.823 & 0.677 & & \\
\hline & NE4 & 0.819 & 0.670 & & \\
\hline & NE5 & 0.798 & 0.636 & & \\
\hline \multirow{5}{*}{ Positive emotions } & PE1 & 0.706 & 0.502 & \multirow{5}{*}{0.885} & \\
\hline & PE2 & 0.831 & 0.690 & & \\
\hline & PE3 & 0.729 & 0.531 & & 0.607 \\
\hline & PE4 & 0.803 & 0.644 & & \\
\hline & PE5 & 0.819 & 0.670 & & \\
\hline & Self-ex & sive ben & & & \\
\hline & IS2 & 0.794 & 0.630 & & \\
\hline Inner-self & IS3 & 0.853 & 0.727 & 0.885 & 0.659 \\
\hline & IS4 & 0.786 & 0.617 & & \\
\hline
\end{tabular}




\begin{tabular}{|c|c|c|c|c|c|}
\hline & IS5 & 0.813 & 0.660 & & \\
\hline \multirow{4}{*}{ Social-self } & SS2 & 0.860 & 0.739 & \multirow{4}{*}{0.926} & \multirow{4}{*}{0.758} \\
\hline & SS3 & 0.890 & 0.792 & & \\
\hline & SS4 & 0.858 & 0.736 & & \\
\hline & SS5 & 0.875 & 0.765 & & \\
\hline \multicolumn{6}{|c|}{ Functional benefits } \\
\hline \multirow{2}{*}{$\begin{array}{l}\text { Health } \\
\text { consciousness(Product) }\end{array}$} & HC3 & 0.880 & 0.774 & \multirow{2}{*}{0.873} & \multirow{2}{*}{0.775} \\
\hline & $\mathrm{HC} 4$ & 0.880 & 0.774 & & \\
\hline \multirow{2}{*}{ Store(Outlet) } & STO6 & 0.875 & 0.765 & \multirow{2}{*}{0.868} & \multirow{2}{*}{0.767} \\
\hline & STO7 & 0.876 & 0.767 & & \\
\hline \multicolumn{6}{|c|}{ Trust } \\
\hline \multirow{3}{*}{ Ability } & ABI1 & 0.821 & 0.674 & \multirow{3}{*}{0.879} & \multirow{3}{*}{0.707} \\
\hline & ABI3 & 0.838 & 0.702 & & \\
\hline & ABI4 & 0.863 & 0.744 & & \\
\hline \multirow{3}{*}{ Benevolence } & BEN2 & 0.876 & 0.767 & \multirow{4}{*}{0.911} & \multirow{4}{*}{0.773} \\
\hline & BEN3 & 0.895 & 0.801 & & \\
\hline & BEN4 & 0.866 & 0.749 & & \\
\hline \multirow{3}{*}{ Integrity } & INT2 & 0.851 & 0.724 & & \\
\hline & INT3 & 0.866 & 0.749 & \multirow{2}{*}{0.897} & \multirow{2}{*}{0.744} \\
\hline & INT4 & 0.870 & 0.756 & & \\
\hline
\end{tabular}

Table:2 Discriminant Validity Through Fornell Lacker Criterion

\begin{tabular}{|l|l|l|l|l|l|l|l|l|l|l|l|l|l|l|l|l|l|}
\hline & ABILIT & BEN & HC & INT & IS & LC & NC & NE & OG & PE & PRI & REG & SD & SEC & SS & STORE \\
\hline ABILIT & 0.841 & & & & & & & & & & & & & & & \\
\hline BEN & 0.602 & 0.879 & & & & & & & & & & & & & & \\
\hline HC & 0.425 & 0.446 & 0.880 & & & & & & & & & & & & & \\
\hline INT & 0.633 & 0.705 & 0.475 & 0.863 & & & & & & & & & & & & \\
\hline IS & 0.373 & 0.315 & 0.257 & 0.293 & 0.812 & & & & & & & & & & & \\
\hline LC & 0.039 & 0.035 & 0.010 & 0.023 & 0.197 & 0.913 & & & & & & & & & & \\
\hline NC & 0.093 & 0.084 & -0.059 & 0.037 & 0.152 & 0.656 & 0.851 & & & & & & & & & \\
\hline NE & 0.162 & 0.149 & 0.090 & 0.156 & 0.336 & 0.202 & 0.138 & 0.813 & & & & & & & & \\
\hline OG & 0.253 & 0.354 & 0.183 & 0.335 & 0.198 & 0.304 & 0.281 & 0.202 & 0.831 & & & & & & & \\
\hline PE & 0.438 & 0.371 & 0.316 & 0.368 & 0.540 & 0.313 & 0.291 & 0.423 & 0.279 & 0.779 & & & & & & \\
\hline PRI & 0.341 & 0.327 & 0.220 & 0.364 & 0.313 & 0.266 & 0.267 & 0.253 & 0.496 & 0.377 & 0.843 & & & & & \\
\hline REG & 0.258 & 0.299 & 0.203 & 0.254 & 0.274 & 0.290 & 0.181 & 0.202 & 0.400 & 0.382 & 0.408 & 1.000 & & & & \\
\hline SD & 0.198 & 0.186 & 0.150 & 0.215 & 0.239 & 0.256 & 0.239 & 0.230 & 0.419 & 0.357 & 0.494 & 0.384 & 0.874 & & & \\
\hline SEC & 0.338 & 0.356 & 0.267 & 0.368 & 0.361 & 0.299 & 0.293 & 0.264 & 0.531 & 0.476 & 0.659 & 0.506 & 0.543 & 0.823 & & \\
\hline SS & 0.254 & 0.178 & 0.137 & 0.134 & 0.617 & 0.179 & 0.198 & 0.326 & 0.194 & 0.375 & 0.259 & 0.201 & 0.249 & 0.294 & 0.871 & \\
\hline STORE & 0.556 & 0.477 & 0.348 & 0.546 & 0.261 & 0.089 & 0.127 & 0.087 & 0.250 & 0.276 & 0.289 & 0.155 & 0.209 & 0.309 & 0.126 & 0.876 \\
\hline
\end{tabular}


Table: 3 Predictive Relevance $\left(\mathrm{Q}^{2}\right)$ Through Blindfolding And Coefficient Of Determination $\left(\mathrm{R}^{2}\right)$

\begin{tabular}{|c|c|c|}
\hline Endogenous Latent Variable & $\mathbf{R}^{\mathbf{2}}$ Value & $\mathbf{Q}^{2}$ Value \\
\hline Ability & 0.707 & 0.497 \\
\hline Benevolence & 0.785 & 0.606 \\
\hline Integrity & 0.802 & 0.596 \\
\hline Trust & 0.528 & 0.296 \\
\hline
\end{tabular}

Table:4 Assessment of PLS Path Model Without The Inclusion Of Mediators.

\begin{tabular}{|l|c|r|c|c|}
\hline \multicolumn{1}{|c|}{ Relation } & $\begin{array}{c}\text { Path } \\
\text { coefficie } \\
\text { nt }\end{array}$ & $\begin{array}{c}\text { p- } \\
\text { value }\end{array}$ & $\begin{array}{c}t- \\
\text { value }\end{array}$ & $\begin{array}{c}\text { Bias corrected } \\
95 \% \text { confidence } \\
\text { interval }\end{array}$ \\
\hline CP -> EB & -0.001 & 0.065 & $\mathbf{2 . 5 9 5}$ & $(-0.002,0.164)$ \\
\hline CP -> TRUST & -0.081 & 0.010 & 1.847 & $(0.007,0.164)$ \\
\hline CC -> EB & 0.866 & 0.387 & 0.866 & $(-0.001,0.002)$ \\
\hline CC -> TRUST & 2.046 & 0.041 & $\mathbf{2 . 0 4 6}$ & $(0.007,0.164)$ \\
\hline CR -> EB & -0.000 & 0.944 & 0.070 & $(-0.001,0.001)$ \\
\hline CR -> TRUST & 2.755 & 0.006 & $\mathbf{2 . 7 5 5}$ & $(0.038,0.207)$ \\
\hline CS -> EB & 2.871 & 0.004 & $\mathbf{2 . 8 7 1}$ & $(0.001,0.004)$ \\
\hline CS -> TRUST & 0.125 & 0.901 & 0.125 & $(-0.075,0.104)$ \\
\hline SE -> TRUST & 0.057 & 0.123 & 1.546 & $(-0.020,0.124)$ \\
\hline EB -> TRUST & 0.565 & 0.007 & $\mathbf{2 . 6 9 5}$ & $(0.511,0.614)$ \\
\hline FB -> TRUST & 0.565 & 0.000 & $\mathbf{2 1 . 2 7 7}$ & $(0.511,0.614)$ \\
\hline ABI -> TRUST & 0.841 & 0.000 & $\mathbf{4 2 . 5 8 5}$ & $(0.799,0.877)$ \\
\hline BEN -> TRUST & 0.886 & 0.000 & $\mathbf{7 1 . 9 2 0}$ & $(0.859,0.907)$ \\
\hline INT -> TRUST & 0.896 & 0.000 & $\mathbf{9 6 . 0 0 6}$ & $(0.875,0.912)$ \\
\hline
\end{tabular}

Note: * - $10 \%$ significance, $* *_{-}$-5\% Significance, $* * *-1 \%$ significance, NS- Not Significant 